\title{
COOPERATIVAS DE TRABALHO NO BRASIL E LEI 12.690/12
}

\author{
Marianna Ferraz Teixeira \\ Abogada \\ Teixeira \& Ferraz Sociedade de Advogados S/S \\ Brasília - Brasil \\ https://orcid.org/0000-0002-3110-5257
}

\section{RESUMO}

A Lei n. 12.690/2012 foi promulgada com o intuito de definir a organização e o funcionamento das Cooperativas de Trabalho e instituir o Programa Nacional de Fomento às Cooperativas de Trabalho. Essa lei trouxe um maior amparo a esse ramo do cooperativismo, que sofreu imensamente os efeitos do termo de conciliação firmado entre a União e o Ministério Público do Trabalho, uma vez que tais tipos de cooperativas foram impedidas de serem contratadas pela Administração Pública, sofrendo preconceito constante e reduzindo as oportunidades para a consecução de sua finalidade. Assim, para compreender as garantias e inovações trazidas com a legislação específica, é necessário entender o cooperativismo de trabalho, a diferenciação do ato cooperativo em relação ao contrato de trabalho, de forma a afastar a relação de emprego e os motivos que acarretaram na fiscalização intensa, bem como os equívocos gerados pela assinatura do termo de conciliação.

PALAVRAS CHAVE: Cooperativas de trabalho, Lei 12.690/12, Ato Cooperativo Contrato de Trabalho, Acordo Judicial, Ministério Público do Trabalho.

CLAVES ECONLIT / ECONLIT DESCRIPTORS: J410, K0, K230.

Cómo citar este artículo/How to cite this article: FERRAZ TEIXEIRA, M.: "Cooperativas de trabalho no Brasil e Lei 12.690/12", CIRIEC-España, Revista Jurídica de Economía Social y Cooperativa, n 39, 2021, pp. 305-326. DOI: 10.7203/CIRIEC-JUR.39.21891 


\section{LABOR COOPERATIVES IN BRAZIL AND LAW 12.690/12}

\section{EXPANDED ABSTRACT}

In Brazil, cooperatives could be divided in seven different branches, according to the Brazilian Cooperatives Organization - responsible for promoting and defending Brazilian cooperative system. This division aims to facilitate the organization and the representation of these societies before the executive, legislative and judiciary powers. Among these branches, only two of them have specific legislation -the credit branch and the labor branch-, the others must follow the national General Law on Cooperatives.

Considering that the labor branch is governed by Law n. 12,690/2012, this paper aims to analyze the historical reasons that led to the enactment of specific legislation and its differences in relation to the General Law on Cooperatives, the problems that involved cooperatives during this period, as well as the national understanding in which concerns the comparisons made between cooperative and labor relations, in order to understand the distinction between the cooperative act and the employment contract.

To this end, through a qualitative investigation, taking into account the historical context of Brazilian labor cooperatives, a deductive approach will be made in view of the extensive literature review on the subject, in order to demonstrate the objectives it proposes, resulting in a deductive study, as it is intended to portray the situation that generated the specific law and its effects in the current reality.

Therefore, it is necessary to note that labor cooperatives emerged during the $19^{\text {th }}$ century with the purpose to reach a better income, better work conditions and a better promotion of the workers, which were not achieved by Industrial Revolution, promoting, this way, a labor independency.

Those cooperatives congregate workers with the same profession or from one same class with identity of interests due to their work activity, who become owners of the capital of the cooperative enterprise and self-managers of common businesses.

The organization of the activity of its members, the preparation of plans to be developed, the offer and signing of contracts, on behalf of its members, with users, as well as the receipt on behalf of the members and the transfer of the entire economic product to the workers are responsibility of the cooperative society, that acts, as a longa manus of the activity performed by the professionals that make up the entity. 
The relation established between cooperatives and member is called cooperative act. The Cooperative Act theory is a Latin American creation based on cooperation, conceived in the Framework Law for Cooperatives in Latin America as those acts performed between cooperatives and their members or by cooperatives among themselves, in fulfillment of their social objective, and must submit to the Cooperative Law. The Legal Charter of San Juan allows the perception of this concept under two aspects. The first restricts the recognition of the act as operationalization or substantiation of cooperation, since it results from the corporate relationship, while the second brings greater amplitude to the recognition of the act, which assumes a constitutive character of cooperation, by becoming the raison d'être of the cooperative.

The cooperative act arises from the cooperative society contract signed between cooperative and its member at the time of voluntary and free entry to participate in the business. This act is the expression of solidarity and democracy that govern cooperativism and has no relation with the employment relation, because the cooperative relationship is based on two principles, that of double quality and that of differentiated personal retribution. While the principle of dual quality alludes that the member must be, at the same time, a member of the cooperative and a client, benefiting from this duality of situations, being legally imposed on cooperatives that provide services to their members, pursuant to article 7 of Law n. 5.764/71, the principle of differentiated personal remuneration allows the cooperative member to receive a personal remuneration higher than what he would obtain if he were not associated.

The employment relationship, on the other hand, is formalized by a labor contract, which is a legal transaction in which the employee, a natural person, provides services in a personal, subordinate and non-eventual manner to the employer, receiving remuneration as consideration. The labor contract, in turn, has the requirements of subordination, personality, onerousness and continuity, and may be tacitly or expressly agreed, verbally or in writing.

None of those requirements could be applied to the relation cooperative and its members. The service hired could be developed by any member of the society, as the cooperative aims the conclusion of the activity itself. Furthermore, the service will be performed for a third party and not for the cooperative, what pushes away the personality. The onerousness cannot also be perceived, because the members subscribe for shares of the capital stock, participate in the assemblies and in surplus for the year based on the annual production, making withdrawals closely related to production, which may vary. Finally, the subordination cannot even be suggested because the cooperative relationship is clearly connected to the affectio societatis and the inspection must be carried out by the auditor, manager or director of the 
cooperative in relation to the service and not the worker, since the cooperative members must manage their time and work.

Despite the non-existence of the employment relationship, during the period of the boom in labor cooperatives, many pseudo-cooperatives were created as a way of circumventing labor legislation and intermediating subordinated labor, especially with Public Administration.

For this reason, the inspection promoted by the Public Ministry of Labor became intense, with the aim of combating fraudulent situations and, with that, a Public Civil Action was filed and culminated in a legal agreement signed between the Union and the PML, preventing the Administration from hiring cooperatives. This act had repercussions in all public spheres until today, despite the numerous criticisms and violations perpetrated by the term.

On July 19, 2012, Law n. 12,690 was published, providing the rules for the organization and functioning of Labor Cooperatives ending the legal uncertainty that hovered over these societies, legally recognizing work cooperatives and guaranteeing rights to their members, by establishing mechanisms to combat labor intermediation cooperatives. By modifying some criteria already established by the General Law of Cooperatives and adding innovations, this rule seeks to consider the principle of concretion to be applied by the Labor Court, to institute the full effectiveness of the cooperative work act, to promote decent work able to bring improvements in the condition of the members' life.

KEYWORDS: Labor Cooperatives, Law 12.690/12, Cooperative Act, Labor Contract, Judicial Agreement, Public Ministry of Labor. 


\section{SUMÁRIO}

1. Introdução. 2. As cooperativas de trabalho. 2.1. 0 ato cooperativo nas cooperativas de trabalho. 2.2. 0 contrato de trabalho. 2.3. Diferenciação entre o contrato de trabalho e o ato cooperativo. 3. As cooperativas de trabalho no Brasil: perspectiva legal. 4. Aspectos históricos que geraram o Termo de Conciliação Judicial AGU-MPT. 5. Críticas ao Termo de Conciliação Judicial AGU-MPT. 6. A Lei 12.690/2012. 7. Conclusões. Referências bibliográficas.

\section{Introdução}

No Brasil, as cooperativas se dividem em sete distintos ramos, definidos pela Organização das Cooperativas Brasileiras (OCB), com o intuito de facilitar a organização e representação dessas sociedades junto aos poderes Executivo, Legislativo e Judiciário. Desses ramos, apenas dois possuem legislação específica -o ramo crédito e o ramo trabalho-, os demais devem seguir a legislação geral do cooperativismo nacional.

Considerando que o ramo trabalho é regido pela Lei n. 12.690/2012, o presente trabalho tem o intuito de analisar as razóes históricas que acarretaram a promulgação de uma legislação específica e suas diferenças com relação da Lei Geral das Cooperativas, os problemas que envolveram as cooperativas durante esse período, bem como o entendimento nacional no que concerne às comparaçóes realizadas entre as relaçóes cooperativas e trabalhistas, a fim de compreender a distinção existente entre o ato cooperativo e o contrato de trabalho.

Para tanto, por intermédio de uma investigação qualitativa, levando em consideração o contexto histórico das cooperativas de trabalho brasileiras, far-se-á uma abordagem dedutiva ante a extensiva revisão de literatura sobre a temática, a fim de demonstrar os objetivos a que se propóe, resultando em um estudo dedutivo, já que se pretende retratar a situação que gerou a lei específica e seus efeitos perante a realidade atual.

Sendo assim, é necessário notar que as cooperativas de trabalho surgiram na França, no final do século XIX, com o intuito de gerar trabalho produtivo, treinamento e proteção ao trabalhador, sem qualquer caráter paternalista ou assistencialista, melhorando a renda de seus associados ao intermediar a prestação de serviços de seus cooperados, expressos em forma de tarefa, obra ou serviço, com os seus contratantes, pessoas físicas ou jurídicas, não produzindo bens ou serviços próprios. 
Essas cooperativas buscam, então, a aproximaçáo da atividade profissional de seus membros ao usuário final dos serviços, sem qualquer tipo de intermediação, atuando como uma longa manus da atividade exercida pelos profissionais que compóem a entidade. Os cooperados deverão ter a mesma profissão ou pertencer a uma mesma classe que congregue identidade de interesses em razão da atividade laborativa, ademais de se tornarem donos do capital do empreendimento cooperativo e autogestores dos negócios comuns.

A relação estabelecida entre a cooperativa e o cooperado não é de emprego, uma vez que decorre do ato cooperativo, que no caso do ramo trabalho é o negócio-fim da cooperativa, sendo celebrado unicamente com os cooperados que se dispuseram a congregar a atividade em proveito comum. Por essa razão a sociedade não pode ser confundida com prestadora, tampouco com tomadora de serviços, uma vez que reúne a atividade de seus membros para a contratação global de seus serviços.

Esse ato tampouco se confunde com o contrato de trabalho, que pressupóe como requisitos a subordinaçáo, a pessoalidade, a onerosidade e a continuidade, nenhum dos quais é vislumbrado em uma cooperativa de trabalho, dada as particularidades de sua atuação tipicamente societária.

Apesar de inexistir essa relaçáo de emprego, durante meados dos anos 90 e início dos anos 2000, tendo em vista o acentuado crescimento do número de cooperativas laborais no Brasil e, consequentemente, a ampliação da fiscalização por parte do Ministério Público do Trabalho, verificou-se que muitas cooperativas foram criadas como forma de intermediar mão-de-obra subordinada, em especial para a Administração Pública, de maneira fraudulenta.

Assim, além da violação às regras administrativas, essas falsas cooperativas não observavam as regras trabalhistas mínimas e necessárias para proteger os trabalhadores, razão pela qual foi ajuizada uma Ação Civil Pública que culminou na assinatura de um Termo de Conciliação Judicial entre a União e o Ministério Público do Trabalho (MPT), que impediu as cooperativas de participarem de contratação com a administração pública.

Esse acordo gerou consequências em todas as esferas estatais, tendo a administração impedido, a partir de então, que as cooperativas participassem de procedimentos licitatórios, impondo, em seus editais, a impossibilidade dessas sociedades em concorrerem ao certâmen, razão pela qual foi editado o enunciado de Súmula n. 281 do Tribunal de Contas da União (TCU).

Assim, diante de todo o preconceito e dos impedimentos gerados, foi necessária a elaboração de uma lei que fomentasse a criação das cooperativas de trabalho, dando-lhes a segurança necessária ao determinar as regras a serem aplicadas, além de combater as falsas cooperativas. Essa lei foi promulgada em 2012, sob o n. 12.690 e tem 
buscado a promoção do trabalho digno daqueles que vislumbram o cooperativismo como uma forma de melhorar sua condição de vida.

\section{As cooperativas de trabalho}

As cooperativas de trabalho tiveram sua origem na França, no final do século XIX, devido a duas condiçóes que favoreceram sua criação: a existência de uma classe operária possuidora tanto de formaçáo profissional como de informação econômica, bem como a liberalidade social e política que reuniu trabalhadores insatisfeitos ${ }^{1}$.

De acordo com o professor Guilherme Krueger, a fonte de inspiração para essa invenção deve-se a um artigo publicado por Philippe Bouchez ${ }^{2}$ e que delimita as características de operacionalização das cooperativas de trabalho até os dias atuais e que, em conjunto com os princípios rochdaleanos, regem esse ramo do cooperativismo.

Tendo em vista que as cooperativas buscam promover a independência laboral do ser humano, sendo um meio eficaz na promoção e no desenvolvimento socioeconômico, as cooperativas laborais tem como objetivo comum alcançar a melhoria de renda de seus associados, a melhoria das condiçóes de trabalho e a melhoria da promoção dos trabalhadores.

A melhoria de renda é possível uma vez que se retém, para os associados, a mais valia, já que recebem o valor total produzido, ademais de ser uma maneira para a correção salarial sobretudo em locais onde existe desequilíbrio entre oferta e procura no mercado de trabalho. Por sua vez, a melhoria das condiçóes de trabalho é atingida

1. Vid. LIMA NETO, A.: Cooperativas de Trabalho: Intermediação de mão-de-obra e subtração de direitos dos trabalhadores, Juruá, Curitiba, 2004, p. 185.

2. Naquela oportunidade, BOUCHEZ formulou um sistema de trabalho por associação, cujas linhas gerais continuam observadas até hoje nas operaçôes realizadas pelas cooperativas de trabalho:

- Os associados assumem a condição de empreendedores, elegendo entre eles um ou mais representantes da sociedade;

- Cada um deles continuaria recebendo uma remuneração segundo os padrốes correntes para cada profissão, ou seja, por jornada ou tarefa e segundo a habilidade individual;

- O valor equivalente à mais-valia se reverteria em benefício líquido, se repartindo da seguinte forma: parte para reservas e investimentos no empreendimento, em assistência para os associados e para distribuição entre os associados, pro rata de seu trabalho;

- Recursos para reserva e investimentos pertencem à sociedade e são indivisíveis entre os associados, a fim de se prevenir que ela se reduza a um mero meio de exploração, igual a qualquer empresa;

- A sociedade náo poderia fazer trabalhar permanentemente em seu benefício trabalhadores estranhos, sendo obrigada a admitir o número necessário de trabalhadores novos que se fizessem necessários pelo aumento das operaçóes realizadas pela sociedade.

Vid. KRUEGER, G.: Cooperativas de trabalho na terceirização, 2. ${ }^{a}$ ed., Editora Del Rey, Belo Horizonte, 2014, pp. 45-46. 
pelo fato de os trabalhadores se tornarem empresários e determinarem em conjunto e democraticamente as regras que regeráo a cooperativa. Por fim, a melhoria da promoção dos trabalhadores se dá pelo fato dos trabalhadores se tornarem autogestionários de suas próprias atividades, demandando, para tanto, constante capacitação e observância aos princípios cooperativistas ${ }^{3}$.

Como finalidade, verifica-se que essas cooperativas buscam a aproximação da atividade profissional de seus membros ao usuário final dos serviços, sem qualquer tipo de intermediação. É de responsabilidade da sociedade a organização da atividade de seus cooperados, a preparaçáo dos planos a serem desenvolvidos, a oferta e a assinatura dos contratos, em nome de seus associados, com os usuários, bem como o recebimento em nome dos membros e o repasse da totalidade do produto econômico dessas contrataçóes a eles, atuando, assim como uma longa manus da atividade exercida pelos profissionais que compóem a entidade .

Esses profissionais serão, então, os trabalhadores da mesma profissão ou não, porém, de uma mesma classe, que possuam identidade de interesses em razão de sua atividade laborativa e que se tornam donos do capital do empreendimento cooperativo e autogestores dos negócios comuns, passando a denominarem-se cooperados.

\subsection{O ato cooperativo nas cooperativas de trabalho}

A teoria do Ato Cooperativo é uma criação latino-americana que tem como base a cooperação, sendo conceituado na Lei Marco para as Cooperativas da América Latina como aqueles atos realizados entre as cooperativas e seus sócios ou pelas cooperativas entre si, em cumprimento de seu objetivo social, devendo submeter-se ao Direito Cooperativo 5 .

3. Vid. PERIUS, V. (org.): Cooperativas de Trabalho - manual de organização, Editora Unisinos, São Leopoldo, 1997, pp. 12-13.

4. Vid. TEIXEIRA JUNIOR, A.B. \& RODRIGUES CIOTTI, L.: Cooperativas de Trabalho e o Termo Judicial de Conciliação Judicial AGU-MPT, Editorial Mandamentos, Belo Horizonte, 2005, pp. 21-22.

5. Artigo 7. São considerados atos cooperativos aqueles realizados entre as cooperativas e seus sócios ou pelas cooperativas entre si, em cumprimento de seu objetivo social e ficam submetidos ao Direito Cooperativo.

Justificativa

Uma noção fundamental que vem ganhando terreno na legislação e a doutrina nos últimos anos é a do "ato cooperativo" - diferente do ato de comércio e de outros atos jurídicos - que este artigo incorpora. O conceito utilizado se limita aos atos realizados entre as cooperativas e seus sócios ou pelas cooperativas entre si, sempre em cumprimento do objeto social. Entretanto, existem outras posiçóes legais e doutrinárias que conferem a esta noção um alcance mais amplo, incluindo, por exemplo, as operaçốes com não associados e ainda todas as operaçóes que as cooperativas realizam para cumprir seu objeto social e, especialmente, o ato constitutivo, sendo este compreendido como o primeiro ato cooperativo gerador de todos os demais. Por isso, postula-se 
De acordo com Guilherme Krueger, a Carta Jurídica de San Juan permite a percepção desse conceito sob dois aspectos. O primeiro restringe o reconhecimento do ato como operacionalização ou consubstanciação da cooperação, uma vez que decorrente da relação societária, enquanto o segundo traz maior amplitude ao reconhecimento do ato, que assume caráter constitutivo da cooperação, ao se tornar a razão de ser da cooperativa ${ }^{6}$.

Doutrinariamente, tem-se que ato cooperativo é a expressão jurídica da solidariedade, do esforço próprio e da ajuda mútua, diferenciando-se do negócio jurídico ordinário, uma vez que este prima pelo enfrentamento das partes. Além disso, os cooperados dirigem o ato cooperativo para si e, por isso, não há agressão à esfera jurídica alheia; nem há possibilidade de uma vontade avassalar outra inerente ao negócio; inexiste, nesse caso, um terceiro estranho ao ato, submetido a uma declaração de vontade na qual não teve participação; não existe fonte de arbitrariedade, sendo, portanto, um ato que conjuga os interesses gerais e individuais dos associados, além de náo prever cláusulas leoninas em razão da essencial igualdade existente entre os membros ${ }^{7}$.

A legislação brasileira, por sua vez, define o ato cooperativo no artigo 79 da Lei n. 5.764/71, afirmando serem os atos cooperativos aqueles praticados entre as cooperativas e seus associados, entre estes e aquelas e pelas cooperativas entre si quando associadas, para a consecução dos objetivos sociais, sem implicar operação de mercado, nem contrato de compra e venda de produto ou mercadoria ${ }^{8}$.

Cabe destacar que esse ato decorre do contrato de sociedade cooperativa, que prevê que as pessoas que se vinculam à cooperativa reciprocamente se obrigam a

que os atos de mercado praticados pela cooperativa, realizados em cumprimento de seu objeto social, vinculados à atividade dos sócios e por conta deles não implicam em renda, faturamento ou qualquer vantagem patrimonial para a cooperativa.

Esclarece-se, como efeito fundamental, que estes atos são submetidos ao Direito Cooperativo com o qual se determina a aplicação de outras figuras ou normas jurídicas estranhas à natureza da cooperativa. Em todos os casos, a relação sócio-cooperativa se rege pelo Direito Cooperativo, que é particularmente importante no caso das cooperativas de trabalho associado a fim de evitar dúvidas sobre a natureza da relaçáo citada.

Vid. ALIANÇA COOPERATIVA INTERNACIONAL PARA AS AMÉRICAS [ACI-Américas]: Lei Marco para as cooperativas de América Latina, Aliança Cooperativa Internacional para as Américas (ACI-Américas), San José, 2009, p. 5.

6. Vid. KRUEGER, G.: Cooperativas de Trabalho na terceirização, Mandamentos, Belo Horizonte, 2003, p. 41.

7. Vid. PASTORINO, R.J.: Teoría General del Acto Cooperativo. Intercoop Editora Cooperativa, Buenos Aires, 1993, pp. 34 e 42.

8. Vid. BRASIL. Lei n. 5.764, de 16 de dezembro de 1971, Acedido em 30 de outubro de 2021, em http:// www.planalto.gov.br. 
contribuir com bens ou serviços para o exercício de uma atividade econômica, de proveito comum, sem objetivo de lucro9 .

Essa relação encontra-se pautada em dois princípios, o da dupla qualidade e o da retribuição pessoal diferenciada. Enquanto o princípio da dupla qualidade alude que o associado deve ser, ao mesmo tempo, cooperado e cliente, auferindo as vantagens dessa duplicidade de situaçóes, sendo legalmente imposto às cooperativas que prestam serviços a seus associados, nos termos do artigo $7^{\circ}$ da Lei n. 5.764/71, o princípio da retribuição pessoal diferenciada permite que o cooperado receba uma retribuição pessoal superior àquilo que obteria caso não estivesse associado.

Sendo assim, pode-se afirmar que o ato cooperativo tem natureza institucional ou estatutária, porquanto decorre dos negócios internos da sociedade ao almejar o interesse exclusivo dos associados.

Em uma cooperativa de trabalho, o ato cooperativo é, portanto, o negócio-fim da cooperativa e é celebrado unicamente com os cooperados que se dispuseram a congregar a atividade em proveito comum e, por isso, náo pode ser confundida com prestadora, tampouco com tomadora de serviços, uma vez que reúne a atividade de seus membros para a contratação global de seus serviços.

\subsection{O contrato de trabalho}

O Direito do Trabalho pode ser definido como "o ramo da ciência do direito que tem por objeto as normas, as instituiçóes jurídicas e os princípios que disciplinam as relaçóes de trabalho subordinado, determinam os seus sujeitos e as organizaçóes destinadas à proteção desse trabalho em sua estrutura e atividade" ${ }^{10}$.

Trata-se, portanto, da área do direito que busca resguardar a relaçáo de emprego, formalizada mediante um contrato de trabalho, que, por sua vez, é o negócio jurídico em que o empregado, pessoa natural, presta serviços de forma pessoal, subordinada e não-eventual ao empregador, recebendo a remuneração como contraprestação. É imprescindível, para tanto, a existência de dois sujeitos envolvidos, o empregado e o empregador ${ }^{11}$.

9. Vid. BRASIL. Lei n. 5.764, de 16 de dezembro de 1971, Acedido em 30 de outubro de 2021, em http:// www.planalto.gov.br.

10. Vid. MASCARO NASCIMENTO, A.: Iniciação ao Direito do Trabalho, 31 ed., LTr, São Paulo, 2005, p. 69.

11. Vid. FERRAZ TEIXEIRA, M.; FERRAZ TEIXEIRA, M.: "Comentários ao acórdão do Tribunal Regional do Trabalho da 3a Região de 28/9/2016, Processo 0001924-29.2014.5.03.0134: o Direito Cooperativo 
Délio Maranhão afirma ser contrato de trabalho stricto sensu o negócio jurídico pelo qual uma pessoa física (empregado) se obriga, mediante o pagamento de uma contraprestação (salário), a prestar trabalho não eventual em proveito de outra pessoa, física ou jurídica (empregador), a quem fica juridicamente subordinada ${ }^{12}$, enquanto Orlando Gomes define o contrato de trabalho como "a convenção pela qual um ou vários empregados, mediante certa remuneração e em caráter não eventual, prestam trabalho pessoal em proveito e sob a direção de empregador ${ }^{13}$ ".

A Consolidação das Leis do Trabalho (CLT), em seu artigo 442, dispóe que o "contrato individual de trabalho é o acordo tácito ou expresso, correspondente à relação de emprego" e, de acordo com o seu artigo $3^{\circ}$, será considerado empregado "toda pessoa física que presta serviço de natureza não eventual a empregador, sob a dependência deste e mediante salário". O empregador, em contrapartida, será "a empresa, individual ou coletiva, que assumindo os riscos da atividade econômica, admite, assalaria e dirige a prestação pessoal de serviço", nos termos do art. $2^{0^{14}}$.

Cabe salientar que o professor Luiz de Pinho Pedreira da Silva aduz que a relação de emprego pressupóe a subordinação hierárquica, elemento que caracteriza o contrato de trabalho ${ }^{15}$.

Desse modo, vislumbra-se que o contrato de trabalho possui como requisitos a subordinação (elemento fundamental para a caracterização desse contrato ${ }^{16}$ ), a pessoalidade, a onerosidade e a continuidade, podendo ser acordado de forma tácita ou expressa, verbalmente ou por escrito.

e o Direito do Trabalho, conflitos e educação", Cooperativismo e Economía Social (CES), no 39, 2016-2017, p. 258.

12. Vid. SÜSSEKIND, A. et al:: Instituiçôes de Direito do Trabalho, Vol. 1, 22a ed., LTr, São Paulo, 2005, p. 241.

13. Vid. GOMES, O. \& GOTTSCHALK, E.: Curso de Direito do Trabalho, Forense, Rio de Janeiro, 1990, p. 130.

14. Vid. BRASIL. Consolidação das Leis do Trabalho, Lei n. 5.452, de $1^{\circ}$ de maio de 1943. Acedido em 30 de outubro de 2021, em http://www.planalto.gov.br.

15. Vid. PINHO PEDREIRA DA SILVA, L: "As concepçôes da relação de trabalho", Revista dos Tribunais, Revista de Direito do Trabalho, no 33(127), 2007, pp. 132-145.

16. Tendo em vista que a subordinação é o elemento fundamental para a caracterização desse tipo contratual, esclarece-se que ela nada mais é que o direito geral de fiscalizaçâo da atividade de outrem, bem como o direito de interromper ou suscitar essa atividade ou, ainda, de limitá-la sem a necessidade de controlar continuamente o valor do trabalho efetuado. Desse modo, os seus dois pilares centram-se na direção e fiscalização.

Vid. FERRAZ TEIXEIRA, M.: "A indevida aplicação do enunciado de Súmula n. 281 do Tribunal se Contas da União e a proibição da participação de Cooperativas de Trabalho brasileiras em procedimentos licitatórios", Deusto Estudios Cooperativos (DEC), no 17, 2021, pp. 82-83. 


\subsection{Diferenciaçáo entre o contrato de trabalho e o ato cooperativo}

Tendo em vista que a relação de emprego se conforma pela celebração de um contrato de trabalho, que pressupóe alguns requisitos indispensáveis, verifica-se que a relação travada entre a cooperativa e seu cooperado náo se encaixa nesse tipo contratual, não devendo, por isso, serem aplicadas as regras laborais a essa situação particular.

A característica da pessoalidade indica que o contrato de trabalho somente poderá ser empregado a uma pessoa física, ou seja, tem um caráter intuitu personae. Essa característica não se aplica ao trabalho cooperativado, uma vez que a contrataçáo para prestação de um serviço por intermédio da cooperativa objetiva, ao fim e ao cabo, a realização da tarefa contratada, independentemente da pessoa que o realizará, que poderá ser exercida por qualquer membro da sociedade, o que afasta a pessoalidade. Além disso, a prestação do serviço por esses trabalhadores se dará em relação a terceiros, uma vez que os cooperados náo prestam serviços a sua própria cooperativa ${ }^{17}$.

Outro requisito inerente ao contrato de trabalho é a onerosidade, que implica que a relação laboral seja retribuída pecuniariamente, que haja o pagamento de um salário. Trata-se de um encargo bilateral natural e próprio da relação de emprego.

Nas cooperativas de trabalho, esse aspecto tampouco é observado. Os cooperados, ao ingressarem nas cooperativas, devem subscrever cotas partes do capital social, participar das assembleias e nas sobras do exercício com base na produção anual. É possível, ainda, que realizem retiradas, definidas estatutariamente, não inferiores ao piso da categoria profissional ou ao salário mínimo, na ausência de um piso previamente estipulado, o que não caracteriza um salário, mas uma antecipação de verba que está intimamente relacionada à produção, sendo, portanto, variável ${ }^{18}$.

Ademais, o pagamento é feito pelo tomador de serviços à cooperativa e não ao prestador de serviços. Cabe à cooperativa, posteriormente, realizar a distribuição desse valor a cada um de seus cooperados tendo por base a produção de cada um de seus membros.

O elemento fundamental, constante e insubstituível para a formação do contrato de trabalho, a subordinaçãa ${ }^{19}$, também não se apresenta na relação cooperativista,

17. Vid. SILVA FILHO, C.V.: Cooperativas de Trabalho, Editorial Atlas, São Paulo, 2002, pp. 82-85.

18. Vid. PINTO MARTINS, S.: Cooperativas de Trabalho, Editorial Atlas, São Paulo, 2003, pp. 93-94.

19. Subordinação, como entendemos, de forma geral, é a situação fática-jurídica, por meio da qual, dentro de uma organização estatal ou privada, alguém assume a condição de observar práticas de comportamentos preestabelecidas, limitando de forma livre a autonomia de sua vontade e sujeitando-se, por uma via de consequência direta, às sançôes previstas e decorrentes de suas atividades e, de sua conduta contrárias às normas. É um fator, inegavelmente, que se faz presente e que se verifica em toda e qualquer modalidade de organização, independentemente da condiçáo jurídica da pessoa em relação à entidade.

Vid. SILVA FILHO, C.V., op. cit., p. 89. 
que é estabelecida em razão da affectio societatis ${ }^{20}$, ou seja, na intenção de constituir a sociedade, de ser membro, da vontade associativa.

Sergio Pinto Martins aduz que nas cooperativas há uma associação de pessoas com objetivos comuns, com o intuito de serem sócios do negócio e de assumirem os riscos a ele inerentes, o que não se vislumbra em um contrato de trabalho ${ }^{21}$.

Outro aspecto importante para o afastamento da subordinação é verificado quanto ao gerenciamento e supervisão do trabalho. No caso de prestaçáo de serviços por intermédio de cooperativas de trabalho, o controle não é realizado com relação à pessoa do trabalhador, mas quanto ao trabalho em si e nunca pelo tomador de serviços e sim pelo auditor, gestor ou diretor da cooperativa. Os cooperados deverão gerenciar o seu tempo e trabalho.

Cabe destacar, ainda, que o parágrafo único do artigo $442 \mathrm{da}$ CLT dispõe que "qualquer que seja o ramo de atividade da sociedade cooperativa, não existe vínculo empregatício entre ela e seus associados, nem entre estes e os tomadores de serviços daquela"22.

Por essa razão, inexiste relação de emprego em uma relação cooperativista, devendo ser afastada a aplicação das normas trabalhistas no trabalho exercido pelos cooperados.

\section{As cooperativas de trabalho no Brasil: perspectiva legal}

A primeira vez que as cooperativas foram tratadas em uma legislação brasileira ocorreu em 1932, com o advento do Decreto 22.239, que, em seu artigo 21 enumerava esse ramo do cooperativismo dentre as distintas formas de cooperativas e, em seu artigo 24, disciplinava que seriam aquelas constituídas por operários de uma determinada profissão ou ofício, ou de distintos ofícios de uma mesma classe, com a finalidade de melhorarem as condiçóes de trabalho e os salários dos associados, sem

20. O que concluímos, afinal, para o estudo que estamos a desenvolver, é que a affectio societatis é um elemento característico do contrato societário de grande utilidade para distinguir a sociedade de outros tipos de contrato que tendem a confundir-se - tal qual o contrato de trabalho -, mesmo que aparentemente. O conceito é subjetivo, o elemento é intencional e se deve perquirir dos reflexos aparentes e exteriores, se a intenção do agente foi a de direcionar esforços para obter resultados comuns, que isoladamente náo seriam táo plenamente conseguidos.

Vid. ibid., p. 92.

21. Vid. PINTO MARTINS, S., op. cit., p. 94.

22. Vid. BRASIL. Consolidação das Leis do Trabalho, Lei n. 5.452, de $1^{\circ}$ de maio de 1943. Acedido em 30 de outubro de 2021, em http://www.planalto.gov.br. 
a intervenção de um patrão ou empresário quando da contratação ou execução de obra, tarefa, trabalhos ou serviços ${ }^{23}$.

A Lei Geral do Cooperativismo, Lei n. 5.764/71, definiu a política nacional de cooperativismo e instituiu o regime jurídico das sociedades cooperativas em território brasileiro, sem explicitar as diferenças de cada um dos ramos adotados pelas cooperativas no país. Essa lei estatuiu a inexistência de vínculo empregatício entre as cooperativas e seus associados ${ }^{24}$, entendimento acrescido à CLT, no parágrafo único do artigo 442, por intermédio da promulgação da Lei n. 8.949/94.

Atualmente, as cooperativas de trabalho brasileiras encontram-se disciplinadas em legislação própria, Lei n. 12.690/2012, definindo-as, em seu artigo $2^{\circ}$, como "a sociedade constituída por trabalhadores para o exercício de suas atividades laborativas ou profissionais com proveito comum, autonomia e autogestão para obterem melhor qualificação, renda, situação socioeconômica e condiçôes gerais de trabalho ${ }^{25 "}$.

\section{Aspectos históricos que geraram o Termo de Conciliaçáo Judicial AGU-MPT}

Entre os anos de 1994 e 1997 houve um crescimento exponencial na criação de cooperativas de trabalho no Brasil, tanto daquelas consideradas genuínas, como daquelas que se utilizavam do arcabouço cooperativo para propagar situaçōes fraudulentas de trabalho ${ }^{26}$.

Essa situação foi gerada pelo advento da Lei n. 8.949/94, já que com a consolidação do entendimento quanto à inexistência do vínculo de emprego na relação estabelecida entre cooperativa e cooperado, sindicatos e federaçóes patronais recomendavam a constituiçáo de cooperativas de trabalhadores, a fim de que se evitassem conflitos trabalhistas perante a Justiça do Trabalho.

23. Vid. BRASIL. Decreto n. 22.239, de 19 de dezembro de 1932, Acedido em 30 de outubro de 2021, em http://www.planalto.gov.br.

24. Art. 90. Qualquer que seja o tipo de cooperativa, não existe vínculo empregatício entre ela e seus associados. Vid. BRASIL. Lei n. 5.764, de 16 de dezembro de 1971, Acedido em 30 de outubro de 2021, em http://www. planalto.gov.br.

25. Vid. BRASIL. Lei n. 12.690, de 19 de julho de 2012, Acedido em 30 de outubro de 2021, em http://www. planalto.gov.br.

26. Vid. HAULY, L.C.: "Cooperativas de trabalho - projetos de lei em debate". Em: Cooperativas de Trabalho: anais do seminário (coords. SILVA MARTINS FILHO, I.G. \& SALABERRY FILHO, M.), LTr, São Paulo, 2004, p. 121. 
Cabe destacar, também, que essa situaçáo permitiu que os empresários que se utilizavam do formato cooperativo de forma irregular para realizar sua atividade obtivessem uma redução nos custos das obrigações trabalhistas, uma vez que o trabalhador passou a ser considerado cooperado e não mais empregado, bem como reduzissem a carga tributária, já que a contribuição patronal para a seguridade social diminuiu ${ }^{27}$.

Ressalte-se que embora a inclusáo da emenda à CLT realizada em 1994 buscasse garantir segurança jurídica e econômica às cooperativas de trabalhadores, o que se viu, na prática, foi a proliferação de falsas cooperativas de trabalho em setores típicos da terceirização, como limpeza, segurança, manutenção, auxílio a escritórios, recepção ${ }^{28}$, ou seja, foram instituídas cooperativas com o fim exclusivo de prestar serviços não especializados a terceiros ${ }^{29}$.

Esse crescimento, por óbvio, não passou despercebido pelo Ministério Público do Trabalho, que passou a redobrar sua atenção sobre as cooperativas de trabalho, fiscalizando-as com maior intensidade. A investigação revelou que inúmeras cooperativas funcionavam, na realidade, como agências de locação de mão de obra para fornecimento de trabalhadores, de maneira indiscriminada, para os órgãos da Administração Pública sem que houvesse o respeito mínimo às normas de proteção ao trabalho e às regras de contratação administrativa.

Sendo assim, no final do ano de 1999, o Ministério Público do Trabalho, por intermédio da Procuradoria Regional da $10^{\text {a }}$ Região - que congrega o Distrito Federal e o estado do Tocantins - passou a investigar duas cooperativas de trabalho que promoviam ,segundo denúncias, intermediação ilegal de mão-de-obra, ao fornecerem para órgáos públicos federais trabalhadores para o exercício de atividades que deveriam ser executadas por servidores concursados ou empregados de empresas terceirizadas. Essa investigação culminou no ajuizamento da Ação Civil Pública n. $1.082 / 02$, em outubro de $2002^{30}$.

No curso desse processo foi, entáo, firmado entre o MPT e a União, sem a oitiva de qualquer das cooperativas rés, um acordo, homologado pelo juízo da $20^{\text {a }}$ Vara do Trabalho de Brasília, que dispunha que as cooperativas deveriam se abster de fornecer

27. Vid. RANGEL ROSSO NELSON, R.A.: "O uso fraudulento das cooperativas de trabalho - instrumento de violação dos direitos mínimos sociais”, Derecho y cambio social, no 53, 2018, pp. 4-5.

28. Vid. MARINHO PEREIRA, C. \& PEREIRA SILVA, S.: "A nova lei de Cooperativas de Trabalho no Brasil: novidades, controvérsias e interrogaçôes”, Mercado de Trabalho: conjuntura e análise, no 53, 2012, p. 69.

29. Vid. TEIXEIRA JUNIOR, A.B. \& RODRIGUES CIOTTI, L., op. cit., pp. 39-41.

30. Vid. ibid., pp. 66-69. 
mão-de-obra para pessoas jurídicas de direito público, sob pena de multa, além de indenização por dano moral coletivo fixada em $\mathrm{R} \$ 500.000,00$ (quinhentos mil reais) $^{31}$.

Esse acordo gerou inúmeros desdobramentos posteriores em toda a Administração Pública, sobretudo com editais contendo cláusulas proibitivas de participação de cooperativas em licitações.

Devido a isso, em 2012, mais precisamente em 11 de julho, foi aprovado o enunciado de Súmula n. 281 do TCU, que impede as cooperativas de participarem de procedimentos licitatórios ${ }^{32}$, demonstrando os efeitos negativos dessa investigaçáo iniciada ainda nos anos 90.

\section{Críticas ao Termo de Conciliação Judicial AGU-MPT}

A assinatura do Termo de Conciliação Judicial entre a Uniáo e o MPT apresenta alguns problemas relevantes. $\mathrm{O}$ primeiro deles diz respeito ao fato da terceirização realizada por cooperativas ser táo lícita quanto à aplicada às sociedades comerciais, desde que siga as mesmas regras. $\mathrm{O}$ segundo ampara-se no fato de a Constituição Federal tutelar o incentivo ao cooperativismo, enquanto o terceiro diz respeito ao princípio da isonomia, respeitando a diferença entre pessoas desiguais.

Nesse sentido, cabe considerar que o $\$ 1^{\circ}$, do artigo $3^{\circ}$, da Lei 8.666/93 - Lei de Licitaçôes -, dispốe que é vedada a inclusão de cláusulas ou condiçóes que restrinjam as cooperativas ${ }^{33}$.

Além disso, o acordo firmado trata-se de uma clara ofensa ao processo legislativo ao invadir a competência prevista na norma constitucional, ampliando a previsão do Decreto n. 2.271/97 quanto aos serviços passíveis de execução indireta, com o intuito de excluir as cooperativas da prestaçáo tanto de atividades fim como de atividades meio no âmbito da administração pública.

31. Vid. ibid., pp. 69-70.

32. Vid. SÚMULA No 281.

É vedada a participação de cooperativas em licitação quando, pela natureza do serviço ou pelo modo como é usualmente executado no mercado em geral, houver necessidade de subordinação jurídica entre o obreiro e o contratado, bem como de pessoalidade e habitualidade.

Vid. BRASIL. Súmula no 281 do Tribunal de Contas da União. Acedido em 30 de outubro de 2021, em http:// www.portal.tcu.gov.br.

33. Vid. BRASIL. Lei n. 8.666, de 21 de junho de 1993. Acedido em 31 de outubro de 2021, em http://www. planalto.gov.br. 
Diante disso, tem-se que o impedimento exarado no acordo viola frontalmente o dispositivo constitucional que determina que as leis estatais deverão apoiar e estimular o cooperativismo ${ }^{34}$.

No entanto, não houve inobservância somente no que diz respeito à Constituição, os princípios administrativos também foram feridos.

O princípio da legalidade foi violado, primeiro por a lei de licitaçóes vedar cláusulas restritivas às cooperativas, assim como por ofender o processo legislativo e usurpar competências administrativas ao ampliar o rol previsto no Decreto n. 2.271/97. O princípio da igualdade também foi desrespeitado, ao tratar distintamente os administrados, no caso, as cooperativas de trabalho, apesar da existência de dispositivo legal que impede esse tratamento discriminatório. Outro princípio que foi infringido é o da competitividade, necessário ao ato, uma vez que impede que a Administração Pública tenha acesso, de fato, à proposta mais vantajosa ao excluir interessados ${ }^{35}$.

Por essa razão e tendo em vista todos os problemas enfrentados pelas cooperativas de trabalho genuínas, foi necessária a elaboração de uma norma específica que, além de impor as diretrizes, protegesse esse ramo do cooperativismo.

\section{A Lei 12.690/2012}

Em 19 de julho de 2012, foi promulgada da Lei n. 12.690, que dispóe sobre a organização e o funcionamento das Cooperativas de Trabalho e institui o Programa Nacional de Fomento às Cooperativas de Trabalho - PRONACOOP. Naquilo que não colidir com a mencionada legislação, também serão aplicadas às cooperativas de trabalho a Lei n. 5.764/71 (Lei Geral do Cooperativismo) e o Código Civil.

Essa norma buscou encerrar a insegurança jurídica que pairava sobre essas sociedades, reconhecendo juridicamente as cooperativas de trabalho e garantindo direitos aos seus membros, ao fixar mecanismos de combate às cooperativas de intermediação de mão de obra e estabelecer a Relação Anual de Informaçóes das Cooperativas de Trabalho (RAICT), promovendo o cooperativismo conforme Recomendação n. 193 da Organização Internacional do Trabalho $(\mathrm{OIT})^{36}$.

34. Art. 174. Como agente normativo e regulador da atividade econômica, o Estado exercerá, na forma da lei, as funçôes de fiscalização, incentivo e planejamento, sendo este determinante para o setor público e indicativo para o setor privado

$\$ 1^{\circ}$ A lei estabelecerá as diretrizes e bases do planejamento do desenvolvimento nacional equilibrado, o qual incorporará e compatibilizará os planos nacionais e regionais de desenvolvimento.

$\$ 2^{\circ}$ A lei apoiará e estimulará o cooperativismo e outras formas de associativismo.

Vid. BRASIL. Constituição de República Federativa do Brasil de 1988. Acedido em 31 de outubro de 2021, em http://www.planalto.gov.br.

35. Vid. TEIXEIRA JUNIOR, A.B. \& RODRIGUES CIOTTI, L., op. cit., pp. 117-137.

36. Vid. MARINHO PEREIRA, C. \& PEREIRA SILVA, S., op. cit., p. 65. 
A Lei n. 12.690/2012 trouxe uma definição de cooperativa de trabalho em seu artigo $2^{\circ}$, sendo, pois, a sociedade constituída por trabalhadores para o exercício de suas atividades laborativas ou profissionais com proveito comum, autonomia e autogestão para obterem melhor qualificação, renda, situação socioeconômica e condições gerais de trabalho. Considera-se, nos termos da lei, autonomia como aquela exercida de forma coletiva e coordenada, mediante a fixação, em Assembleia Geral, das regras de funcionamento da cooperativa e da forma de execução dos trabalhos, enquanto a autogestấo será o processo democrático no qual a Assembleia Geral definirá as diretrizes para o funcionamento e as operaçóes da cooperativa e os sócios decidirão sobre a forma de execução dos trabalhos.

Essa lei também inovou no ordenamento jurídico brasileiro ao ser a primeira norma a dispor expressamente os princípios que regerão as cooperativas de trabalho, trazendo, ademais dos sete princípios cooperativos tutelados pela Aliança Cooperativa Internacional, alguns princípios relacionados ao trabalho ${ }^{37}$.

Ela também define os tipos de cooperativas de trabalho: de produção - quando constituída por sócios que contribuem com trabalho para a produçáo em comum de bens e a cooperativa detém, a qualquer título, os meios de produção - ou de serviço quando constituída por sócios para a prestação de serviços especializados a terceiros, sem a presença dos pressupostos da relação de emprego.

Ao contrário do que era aplicado sob o advento exclusivo da Lei n. 5.764/71, a Lei n. 12.690/2021 reduziu o número mínimo de associados para constituiçáo da cooperativa laboral para 7 (sete) pessoas, facilitando, assim, a formação desse tipo de sociedade e da promoção do trabalho digno.

Mencionada lei também dispôs sobre os direitos mínimos que os cooperados têm garantidos, nada impedindo que a Assembleia Geral estabeleça outros que achar necessário. Esses direitos são o repouso semanal remunerado, preferencialmente aos

37. Art. $3^{\circ}$ A Cooperativa de Trabalho rege-se pelos seguintes princípios e valores:

I - adesáo voluntária e livre;

II - gestâo democrática;

III - participação econômica dos membros;

IV - autonomia e independência;

$\mathrm{V}$ - educação, formação e informação;

VI - intercooperação;

VII - interesse pela comunidade;

VIII - preservaçáo dos direitos sociais, do valor social do trabalho e da livre iniciativa;

IX - não precarizaçấo do trabalho;

$\mathrm{X}$ - respeito às decisôes de assembleia, observado o disposto nesta Lei;

XI - participação na gestão em todos os níveis de decisão de acordo com o previsto em lei e no Estatuto Social. Vid. BRASIL. Lei n. 12.690, de 19 de julho de 2012, Acedido em 30 de outubro de 2021, em http://www. planalto.gov.br. 
domingos; o repouso anual remunerado; a retirada para o trabalho noturno superior à do diurno; o adicional sobre a retirada para as atividades insalubres ou perigosas e o seguro de acidente de trabalho e sua fruição poderá depender de carência, se imposta pela Assembleia.

Destaque-se, no entanto, que segundo Rocco Rosso Nelson, os direitos elencados na legislação específica se assemelharam em demasia àqueles previstos para a relação de emprego, comprometendo, em parte, a relação cooperativista, já que caracteriza uma contradição do desiderato da lei, que busca evitar a utilização da cooperativa para fraudar as relaçóes empregatícias ${ }^{38}$.

Com relação ao funcionamento, a lei prevê que o objeto social poderá ser qualquer gênero de serviço, operação ou atividade, desde que previsto no Estatuto Social, cabendo à cooperativa utilizar, em sua denominação social, a expressão "Cooperativa de Trabalho".

Ainda quanto a esse aspecto, vislumbra-se a forma de convocação e realização da Assembleia Geral e os assuntos que nela será deliberado, diferenciando-se da Lei n. 5.764/71, ressaltando que caberá à Assembleia Geral Ordinária deliberar, anualmente, sobre a adoção ou náo de diferentes faixas de retirada dos sócios.

A fiscalização desse ramo do cooperativismo ficará a cargo do Ministério do Trabalho e Emprego, que aplicará multa de $\mathrm{R} \$ 500,00$ (quinhentos reais) por trabalhador prejudicado caso a cooperativa intermedeie mão de obra subordinada e, nesse caso, o sócio, dirigente ou o administrador condenado pela prática das fraudes elencadas na lei ficará inelegível para qualquer cargo em Cooperativa de Trabalho, pelo período de até 5 (cinco) anos, contado a partir da sentença transitada em julgado.

De acordo com Guilherme Krueger, os artigos $7^{\circ}$ a 11 compreendem a inteligência da Lei n. 12.690/2021, enquanto os artigos $2^{\circ}$ e $3^{\circ}$ expressam seu coração, ao positivar definiçóes teleológicas com o intuito de ponderar o princípio da concreção que deverá ser aplicado pela justiça do trabalho. Para ele, a lei assume a instituição da plena eficácia do ato cooperativo de trabalho em detrimento da delimitação de sua eficácia perante a CLT ${ }^{39}$.

Portanto, verifica-se que a promulgação de uma lei específica para o ramo trabalho buscou reparar os danos advindos com a criação de falsas cooperativas, amplamente combatidas pelo MPT, ademais de trazer uma segurança para a constituiçáa de novos empreendimentos e direitos para os cooperados a ele se associarão, a fim de que haja, de fato, uma melhora na condição de vida desses trabalhadores por intermédio do exercício de um trabalho digno. 
(pp. 305-326)

\section{Conclusóes}

Embora as cooperativas de trabalho sejam uma maneira lídima de promover a inclusão laboral, a melhora das condiçôes salariais, de vida e, por conseguinte, desenvolverem as condiçóes socioeconômicas daqueles que voluntariamente ingressam na sociedade, no Brasil elas sofrem algumas limitaçóes em virtude do impedimento de participarem de licitaçóes públicas.

Essa situaçáo decorre de uma intensa fiscalização promovida pelo MPT entre 1994 e 2000, em virtude do rápido crescimento do número de cooperativas de trabalho no país e que culminou em uma Ação Civil Pública devido à inobservância das regras laborais, administrativas e cooperativistas por uma parte das sociedades constituídas, uma vez que o foram de maneira irregular, a fim de promover intermediação de mão-de-obra subordinada e não a prestação de serviços especializada, de maneira democrática, autogerida e autônoma.

Assim, devido à assinatura do Termo de Conciliação Judicial entre a Uniáo e o Ministério Público do Trabalho nessa Ação, que impediu a Administração Pública Federal de contratar cooperativas de trabalho, vários atos administrativos posteriores impediram essas sociedades de participarem de procedimentos licitatórios em toda a esfera pública, reduzindo, assim, suas possibilidades de atuação.

Diante disso, foi necessária a elaboração de uma lei que pudesse proteger, fomentar e dar segurança jurídica às cooperativas desse ramo, disciplinando regras específicas e direitos àqueles que dela fizerem parte, ademais de prever normas punitivas para as sociedades constituídas de maneira fraudulenta ou para prestação de serviços impedidos desde o termo de conciliação.

Em julho de 2012, então, nasceu a Lei n. 12.690, que definiu a organização e o funcionamento das Cooperativas de Trabalho e institui o Programa Nacional de Fomento às Cooperativas de Trabalho.

Modificando alguns critérios já estabelecidos pela Lei Geral do Cooperativismo e acrescentando inovaçóes, referida norma busca ponderar o princípio da concreção a ser aplicado pela Justiça do Trabalho, instituir a plena eficácia do ato cooperativo de trabalho, promover o trabalho digno apto a trazer a melhora na condição de vida dos cooperados.

Apesar disso, tendo em vista edição do enunciado de Súmula n. 281 do Tribunal de Contas da União também em julho de 2012, a nova lei deve romper os paradigmas impostos e que ainda reverberam quando se está diante de uma cooperativa de trabalho. 


\section{Referências bibliográficas}

\section{ALIANÇA COOPERATIVA INTERNACIONAL PARA AS AMÉRICAS [ACI-} Américas]: Lei Marco para as cooperativas de América Latina, Aliança Cooperativa Internacional para as Américas (ACI-Américas), San José, 2009.

BRASIL. Decreto n. 22.239, de 19 de dezembro de 1932, Acedido em 30 de outubro de 2021, em http://www.planalto.gov.br.

BRASIL. Consolidação das Leis do Trabalho, Lei n. 5.452, de $1^{\circ}$ de maio de 1943. Acedido em 30 de outubro de 2021, em http://www.planalto.gov.br.

BRASIL. Constituição de República Federativa do Brasil de 1988. Acedido em 31 de outubro de 2021, em http://www.planalto.gov.br.

BRASIL. Lei n. 5.764, de 16 de dezembro de 1971, Acedido em 30 de outubro de 2020, em http://www.planalto.gov.br.

BRASIL. Lei n. 8.666, de 21 de junho de 1993. Acedido em 31 de outubro de 2021, em http://www.planalto.gov.br.

BRASIL. Lei n. 12.690, de 19 de julho de 2012, Acedido em 30 de outubro de 2021, em http://www.planalto.gov.br.

BRASIL. Súmula no 281 do Tribunal de Contas da União. Acedido em 30 de outubro de 2021, em http://www.portal.tcu.gov.br.

FERRAZ TEIXEIRA, M.: "A indevida aplicação do enunciado de Súmula n. 281 do Tribunal se Contas da União e a proibição da participação de Cooperativas de Trabalho brasileiras em procedimentos licitatórios", Deusto Estudios Cooperativos (DEC), no 17, 2021, pp. 75-96, DOI: https://doi.org/10.18543/dec-17-2021pp75-96

FERRAZ TEIXEIRA, M. \& FERRAZ TEIXEIRA, M.: "Comentários ao acórdáo do Tribunal Regional do Trabalho da 3 a Região de 28/9/2016, Processo 000192429.2014.5.03.0134: o Direito Cooperativo e o Direito do Trabalho, conflitos e educação", Cooperativismo e Economía Social (CES), no 39, 2016-2017, pp. 253 274.

GOMES, O. \& GOTTSCHALK, E.: Curso de Direito do Trabalho, Forense, Rio de Janeiro, 1990.

GRUMIERI VALÉRIO, M.A.: "Ainda sobre as cooperativas de trabalho no Brasil", Cadernos de Direito Actual, no 6, 2017, pp. 67-74.

HAULY, L.C.: "Cooperativas de trabalho - projetos de lei em debate". Em: Cooperativas de Trabalho: anais do seminário (coords. SILVA MARTINS FILHO, I.G. \& SALABERRY FILHO, M.), LTr, São Paulo, 2004. 
KRUEGER, G.: Cooperativas de Trabalho na terceirização, Mandamentos, Belo Horizonte, 2003.

KRUEGER, G.: Cooperativas de trabalho na terceirização, 2. ${ }^{\mathrm{a}}$ ed., Editora Del Rey, Belo Horizonte, 2014.

LIMA NETO, A.: Cooperativas de Trabalho: Intermediação de mão-de-obra e subtração de direitos dos trabalhadores, Juruá, Curitiba, 2004.

MARINHO PEREIRA, C. \& PEREIRA SILVA, S.: "A nova lei de Cooperativas de Trabalho no Brasil: novidades, controvérsias e interrogações", Mercado de Trabalho : conjuntura e análise, no 53, 2012, pp. 65-74. http://repositorio.ipea.gov.br/ handle/11058/3829

MASCARO NASCIMENTO, A.: Iniciação ao Direito do Trabalho, 31 ed., LTr, São Paulo, 2005.

PASTORINO, R.J.: Teoría General del Acto Cooperativo, Intercoop Editora Cooperativa, Buenos Aires, 1993.

PERIUS, V. (org.): Cooperativas de Trabalho - manual de organização, Editora Unisinos, São Leopoldo, 1997.

PINHO PEDREIRA DA SILVA, L: "As concepções da relação de trabalho", Revista dos Tribunais, Revista de Direito do Trabalho, no 33(127), 2007, pp. 132-145. Handle: https://hdl.handle.net/20.500.12178/173510

PINTO MARTINS, S.: Cooperativas de Trabalho, Editorial Atlas, São Paulo, 2003.

RANGEL ROSSO NELSON, R.A.: "O uso fraudulento das cooperativas de trabalho - instrumento de violação dos direitos mínimos sociais", Derecho y cambio social, no 53, 2018, pp. 1-18.

SILVA FILHO, C.V.: Cooperativas de Trabalho, Editorial Atlas, São Paulo, 2002.

SÜSSEKIND, A.L., MARANHÃO, D., VIANA, J.S. \& FILHO, J.L.T.: Instituiçôes de Direito do Trabalho. Vol. 1. 22a ed., LTr, São Paulo, 2005.

TEIXEIRA JUNIOR, A.B. \& RODRIGUES CIOTTI, L.: Cooperativas de Trabalho e o Termo Judicial de Conciliação Judicial AGU-MPT, Editorial Mandamentos, Belo Horizonte, 2005. 